"Designs for Europe" begins by reviewing the principal European organizations set up since the War-the Economic Commission for Europe, the Organization for European Economic Co-operation, Western European Union, the North Atlantic Treaty Organization, the Council of Europe, the European Coal and Steel Community, European Economic Community and the European Atomic Energy Commission. It then goes on to Britain's relations with Europe, and emphasizes the strong practical reasons for some rationalization of these organizations.

The concept of a single European Assembly to coordinate the activities, interests and objectives of all these varied and overlapping organizations is generally regarded as unworkable, but Political and Economic Planning suggests that it might be practicable on more limited fronts, particularly separate attempts to rationalize organizations concerned mainly with economic and military affairs, thus avoiding the difficulty of linking economic and military cooperation. It is suggested that the Consultative Assembly of the Council of Europe should become the Assembly of the Organization for European Economic Co-operation while continuing its present varied activities, and that this body might become the principal European economic assembly in which all Western European countries would meet. If a free trade area was established, the Organization for European Economic Co-operation would be the most appropriate body to control its work.

The most successful role of the Economic Com. mission for Europe is considered to be in furthering technical co-operation, and it is emphasized that, wherever possible, duplication of technical co-operation in other economic organizations should be avoided. No valid justification is seen for the continued separate existence of the North Atlantic Treaty Organization and Western European Union, and it is suggested that the Assembly of the latter body might be widened into a North Atlantic Treaty Organization assembly. European co-operation, PEP concludes, is in danger of becoming ineffective, through lack of co-ordination. The whole pattern of European co-operation would be simplified by creating out of existing organizations a general economic and defence assembly for the West.

\section{TORNADOES IN GREAT BRITAIN}

$\mathrm{T}$

HE tornado is a relatively thin, roughly vertical

column of air rotating at very high speed about a central axis in which the pressure is markedly less than in the surrounding air. The reduction of pressure leads to condensation of water vapour in the inflowing air to produce a cloud along the axis of the tornado, shaped roughly like a giant elephant's trunk. In its more intense forms the tornado is the most violent and destructive of small-scale meteorological phenomena. The damage produced is caused. by the direct battering of the high wind, the twisting effect of the very great shear of wind outwards from the axis, the lifting effect of the intense vertical currents along the axis and the explosive effect of the sudden reduction of pressure as the axis crosses buildings. The tornado moves with the general wind-current, causing damage where it touches the ground along a track ranging from a few feet to a hundred yards in width. Tornadoes are always associated with heavy thunderstorms, and the rotation is clearly a dynamical phenomenon associated with convergence of air flow towards an axis, but a fully satisfactory theory explaining all their properties has not yet been produced.

The central plains of the United States in spring suffer more than anywhere else from tornadoes, probably because contrasts between adjacent air masses-in that region and season between air from the Gulf of Mexico and air from the Arctic north of America - are sharper than elsewhere and so produce more intense convection.

In the British Isles destructive tornadoes are comparatively infrequent. An examination of published reports showed a total of fifty-four in the eighty-three years from 1868 to 1950 , and most of these caused only minor damage. However, on May 21, 1950, there formed over the north-west part of the Chilterns a tornado which was more violent than most of those which cause damage in the United States.

This tornado is comprehensively described by Mr. H. H. Lamb in Meteorological Office Geophysical Memoir, No. 99*. Mr. Lamb and Mr. J. Simmonds, then both of the Central Forecasting Office, Dunstable, which was close to the track, made a thorough investigation of the tornado in the days immediately following it. The tornado was first noticed near Wendover, Buckinghamshire, at the western end of the Misbourne Valley, whence it moved north-east. ward to the Fen country, causing serious damage in places where it touched the ground. The place worst affected was Linslade, where damage to the value of $£ 25,000$ occurred. Sheets of corrugated iron were carried for half a mile through the air. The great reduction of pressure in the centre is shown by the fact that it lifted water in a duckpond to a height of $10 \mathrm{ft}$., which affords a rough estimate of the reduction of pressure as about one-third, since the height of the water barometer near sea-level is about $30 \mathrm{ft}$. The only known photograph, reproduced in the Memoir, of a tornado in Britain was taken by an airman at the R.A.F. Station at Halton as this one passed over.

The Memoir gives a full account of the meteorological situation and, from the damage to trees and from winds recorded by anemometers a mile or so from the track, of the structure of the tornado. Mr. Lamb points out that the first tornado and its regenerations occurred at the openings of valleys at right angles to the general wind, where there would be an initial curving of flow to stimulate the spin. The sense of rotation in this instance appears to have been cyclonic (counterclockwise), but this is not always so and a tornado of anticyclonic rotation has since occurred in France (La Météorologie, Paris, 317 ; 1955).

A comparison of the observations with the theories of causes of tornadoes is given. The Memoir concludes with a note on the climatology of tornadoes in Britain which clearly exhibits the correspondence of areas of maximum frequency of both thunderstorms and tornadoes.

It is interesting to note that on the thundery, squally afternoon of December 8,1954 , there was a sharp tornado to the west of London which caused severe damage along a line from Chiswick through Acton to Golders Green. A description with a radar. photograph is given in the Meteorological Mayazine, 84,$320 ; 1955$.

* Air Ministry : Meteorological Office. Geophysical Memoirs, No. 99 Tornadoes in England, May 21,1950 . By H. H. Lamb. Pp. $\mathbf{i}+38+$ 